\title{
Assessment of the impact of railway tunnel lining defects with a long working lifespan on its carrying capacity
}

\author{
Mikhail Pleshko ${ }^{1}$, Ivan Voinov $^{1}$, Alexey Revyakin ${ }^{1}$ \\ ${ }^{1}$ Rostov State Transport University, Rostovskogo Strelkovogo polka sq., 2, Rostov-on-Don, 344038, \\ Russia
}

\begin{abstract}
Assessment of engineering status of railway tunnels with a long working lifespan causes the necessity of definition of the actual stressstrain state of construction design, taking into account the results of inspection of its engineering status. static analysis of lining in this case is performed by finite elements method. In the article the example of such analysis is given. The tunnel is strengthened by the composite tunnel lining consisting of an inner layer of masonry body and a shotcrete outer layer built while rebuilding operation. In response to the inspection considerable variances of the actual lining concrete power of resistance from design value have been revealed, as well as local destructions of a lining and internal voids. It has been estimated that influence of lining concrete resistance power nonhomogeneity leads to decrease in carrying capacity on average by $17.3 \%$. Consideration of inner and outer defects can reduce the carrying capacity by 2-3 times. While that sort of assessment not always allows to reveal dangerous processes in the considered geotechnical system and to realize effective protection measures promptly. In this case it is reasonable to use information modeling on the basis of BIM technologies. In relation to railway tunnels the further enhancement is needed. The following sequence of engineering status assessment of a tunnel while information modeling is proposed: carrying out essential geotechnical and geophysical researches on the route of a tunnel; tunnel structures monitoring system development and deployment, collection and analysis of data; regular control of a tunnel by the railcar with the measuring station; creation of a tunnel digital model, filling it with data, regular updating and checking calculations; development and implementation of essential repair actions.
\end{abstract}

\section{Introduction}

Railway tunnels appertain to the most complex and responsible objects of transport infrastructure. Nowadays tunnels constructed 130-150 years ago are in operation in Europe, the USA, Russia and other countries. Their current state is very often characterized by above-limit abrading, influence of the changing natural and technogenic factors, the 
condensed building of the land surface, increase of transport stresses etc. in this regard, the engineering status assessment of tunnels with a long working lifespan and the development of well-timed actions for its improvement is very urgent.

The solution of this problem causes the necessity of the actual tunnel structure stressstrain definition, taking into consideration the inspection results of its elements, the surrounding rock mass, contact layer "subgrade - lining", the impacts of new construction activity, repair and refurbishment work or rebuilding operation of an object. Static analysis of a system is primarily possible by means of approximate calculation. The finite elements method is the most abundant in practical terms [1-3].

\section{Initial data}

Let us take a closer look at the example of the solution to the problem of actual stress-strain state of the tunnel with a long working lifespan, carried out per the inspection of one of the tunnels in the Southern Federal District of Russia.

The tunnel is strengthened by the composite tunnel lining, consisting of an inner layer of limestone masonry body and a shotcrete outer layer built while rebuilding operation. The analysis results show a number of specific tunnel structure defects.

1. Considerable variances of the actual lining concrete power of resistance from design value (Figure 1).

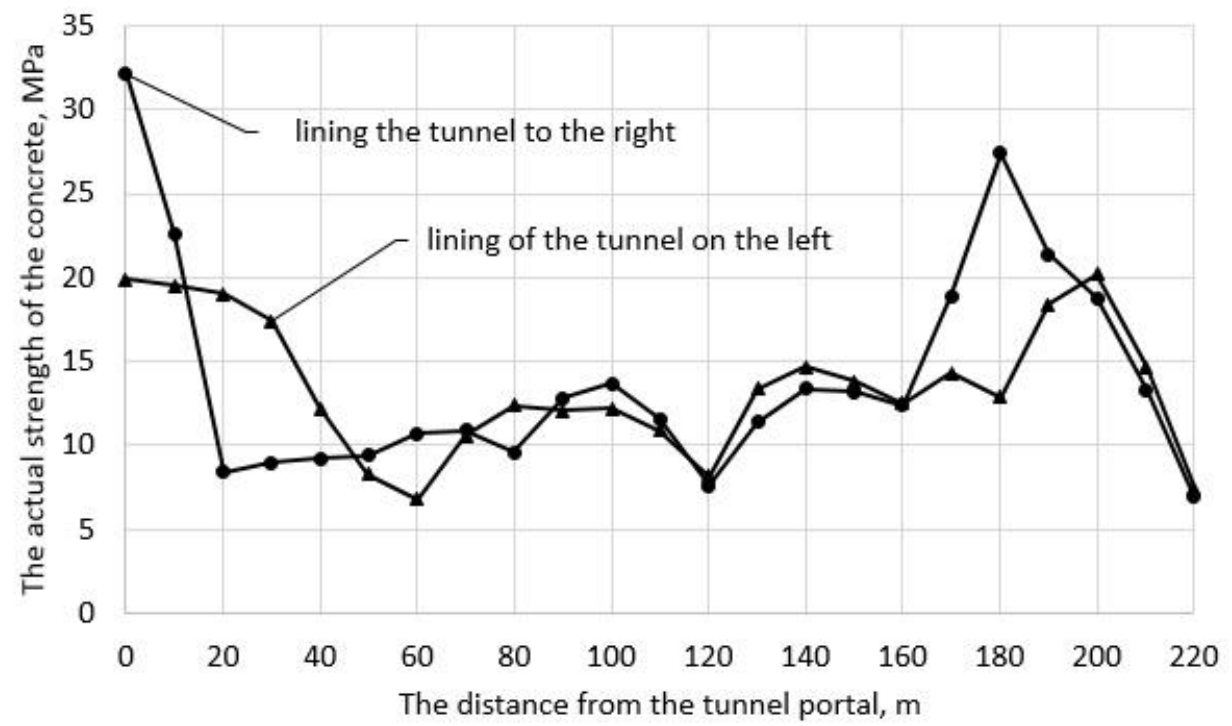

Fig. 1.Diagrams of change in the actual power of resistance of an outer layer concrete lining within tunnel portal distance.

2. Surface damage of a tunnel shotcrete lining outer layer owing to long-term corrosion effect (Figure 2). 


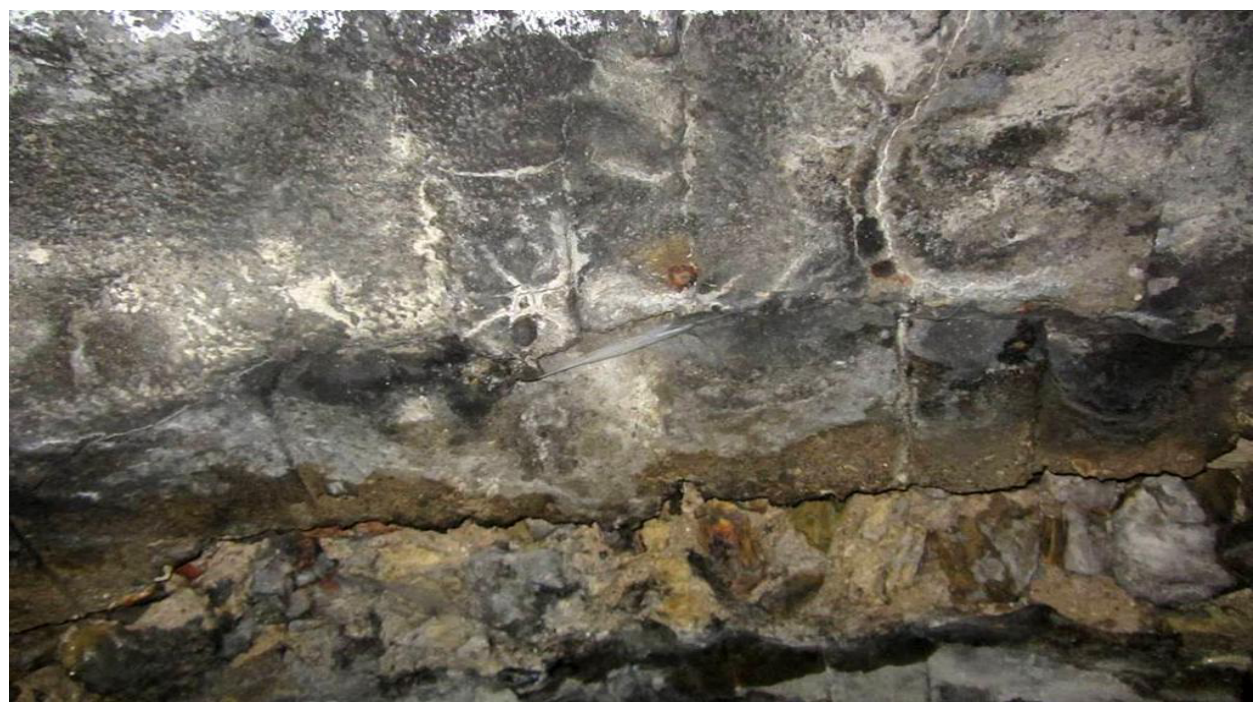

Fig. 2.Surface damage of a tunnel shotcrete lining outer layer owing to long-term corrosion effect.

3. Internal voids between a shotcrete layer and a masonry lining layer revealed by means of lining scaning by the ultrasonic tomograph A1040MIRA (Figure 3).

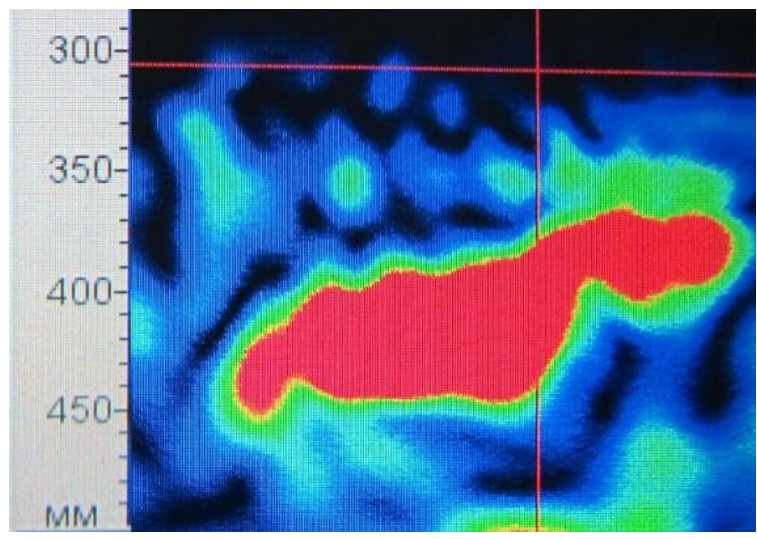

Fig. 3.Beyond lining space voids between shotcrete inner layer and masonry outer layer.

4. The destruction of the lining of the tunnel invert under a ballast section of a railway track revealed at georadar scanning of a tunnel along an axis of a railway track (Figure 4). 


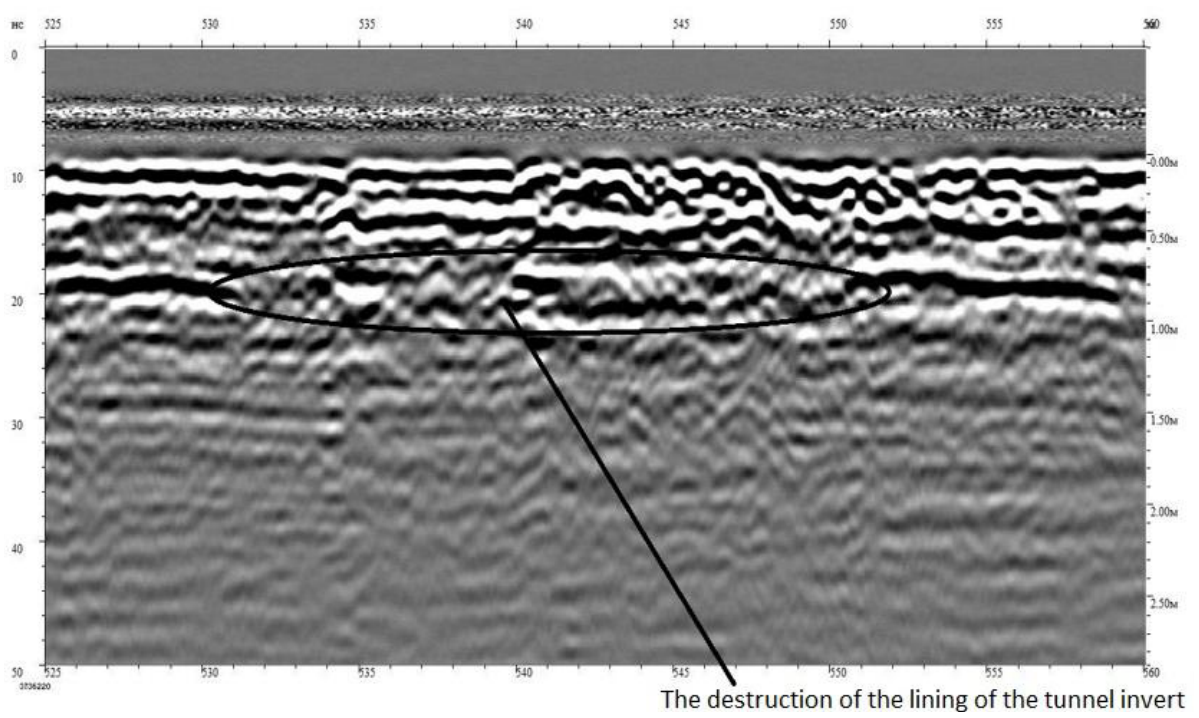

Fig. 4. Results of georadar scanning of the tunnel invert under a ballast section of a railway track.

\section{Model}

Two computing models are developed for the check of the carrying capacity of the tunnel lining. The first model is developed according to the design value, the second takes into consideration the defects revealed during the inspection. The models had a rectangular shape $66 \mathrm{~m}$ wide and $48 \mathrm{~m}$ high. That fact has provided avoidance of boundary conditions on the district of a tunnel lining and the surrounding rock mass.

At creation finite element model grids the principle of combination of the dense and coarse grids is used. Sectional drawing of the lining breaks down into flat slab design (triangled and quadrangular) finite elements (FE) with a size of side of $5-10 \mathrm{~cm}$. The rock mass is presented in the form of a grid of flat slab design FE with gradual increase in the size of sides from 10 to $30 \mathrm{~cm}$.

The rock mass surrounding tunnel is defined as, according to the data of geotechnical open cut, nonhomogeneous, with admixed layers of sand, loam and limestone.

The lining is composite: the inner layer is a masonry of moderate strength, the outer layer is monolithic shotcrete with the changing actual power of resistance in the second model within tunnel portal distance.

At the sectional drawing of the lining of the second model the revealed inner and outer defects are simulated (Figure 5). 


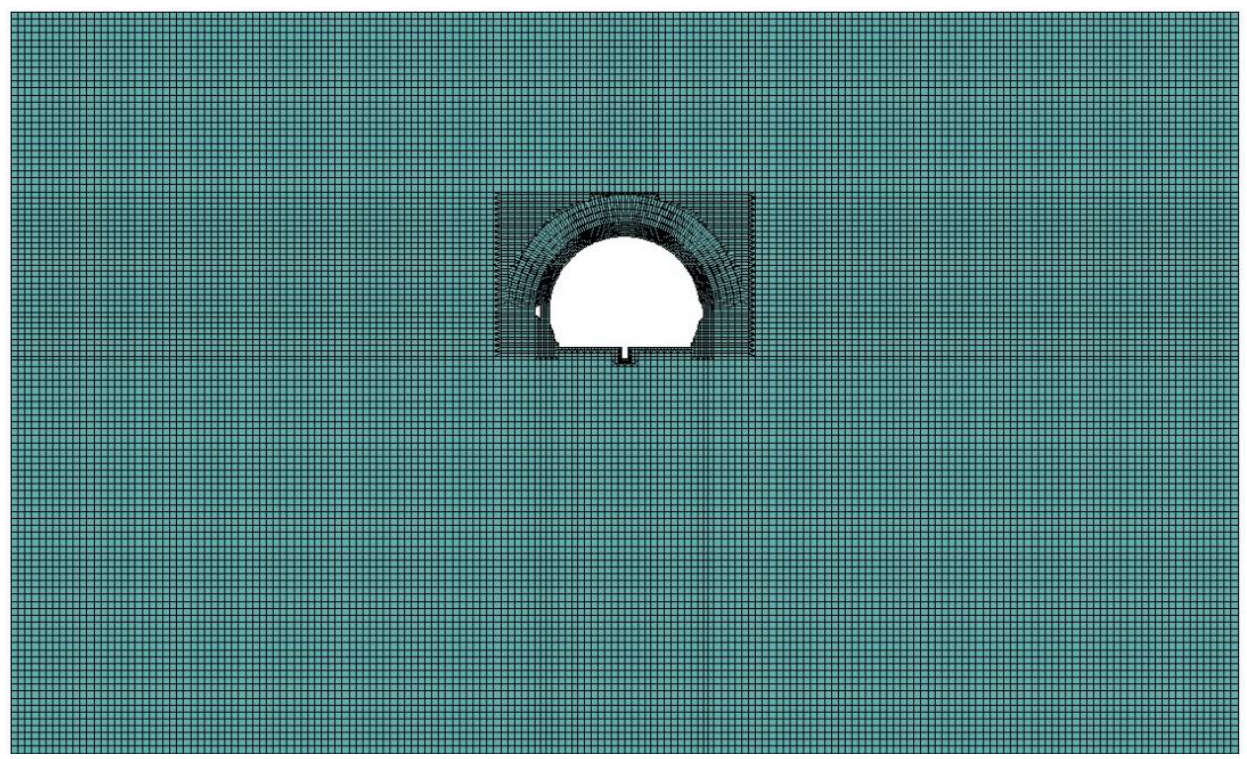

Fig. 5. Computing model of a railway tunnel.

The problem has been considered in secondary stresses with the following boundary conditions: on side surface and lower bound of model constraints in normal to sides offset are set. For finite element of lining the mode of dead load is set. The pressure load from overburden stress are impressed in the form of equilibrium distribution on lining outer boundary. Short-term load from the rolling stock is impressed to the upper side of the soil of a tunnel with due allowance for the loading surface of railway ballast. The problem was solved in elasto-plastic statement. The crossing line of subgrade transition to a postyield state was determined by Mohr-Coulomb failure criterion.

\section{The calculation results}

The calculations of the model found all the components of the stress-strain state of finite elements and nodes. Further the main stress in elements of the lining and the mass was defined.

In Figure 6 isofields of the main stress $\sigma 1$ in a tunnel lining and the surrounding rock mass are presented. 


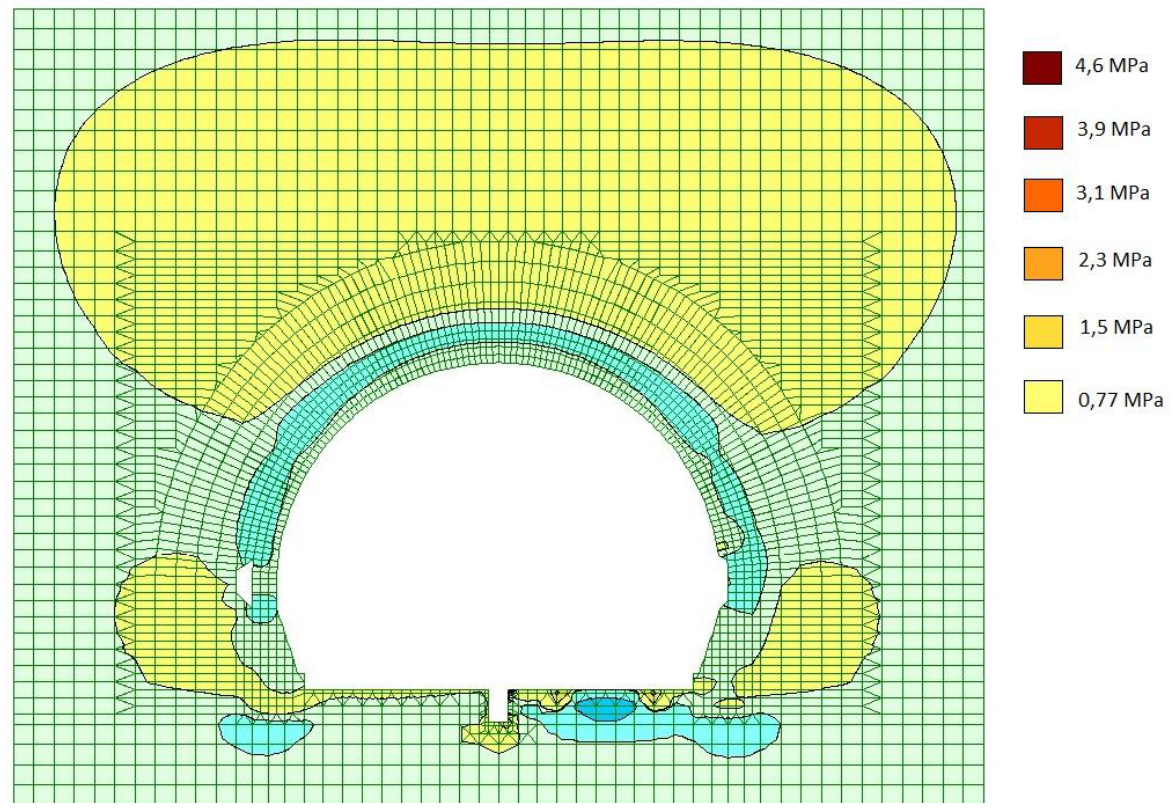

Fig. 6.Isofields of the main stress $\sigma_{3}$ in a tunnel lining and the surrounding rock mass.

InFigure 7 isofields of the main stress $\sigma_{3}$ in a tunnel lining and the surrounding rock mass are presented.

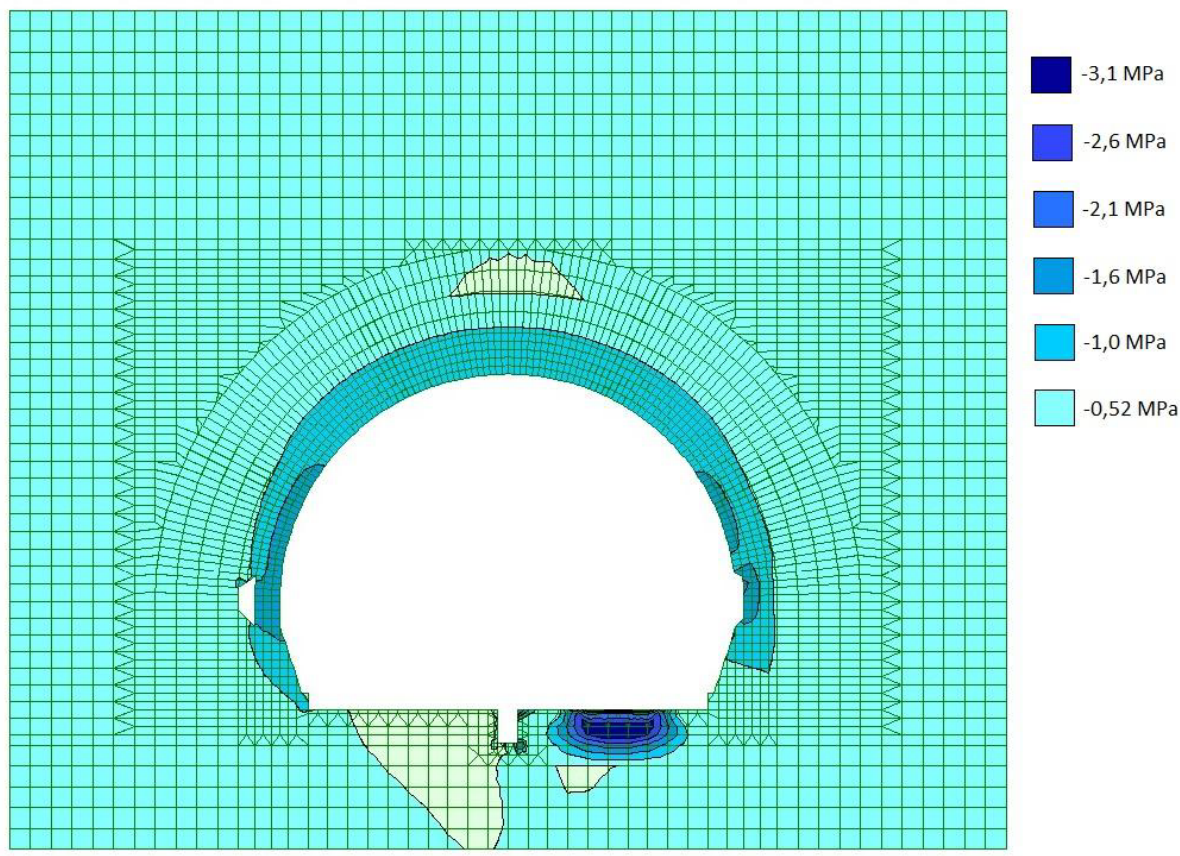

Fig. 7.Isofields of vertical displacement of tunnel lining nodes and surrounding rock mass.

The table 1 gives summarized information of calculation of the model with defects. 
Table 1.Results of calculation of the lining (compressive stress is accepted negative).

\begin{tabular}{|c|c|c|c|}
\hline $\begin{array}{c}\text { Element of lining } \\
\text { structure }\end{array}$ & $\begin{array}{c}\text { Peak } \\
\text { principal stress } \\
\sigma_{3}, \mathrm{MPa}\end{array}$ & $\begin{array}{c}\text { Peak } \\
\text { principal stress } \\
\sigma_{1}, \mathrm{MPa}\end{array}$ & $\begin{array}{c}\text { Maximal } \\
\text { lining displacement, } \\
\mathrm{mm}\end{array}$ \\
\hline Crown & -1.43 & -0.09 & $\begin{array}{c}-40.27 \\
\text { (vertical) }\end{array}$ \\
\hline Left side & -1.55 & 0.83 & $\begin{array}{c}-2.05 \\
\text { (horizontal) }\end{array}$ \\
\hline Right side & -1.84 & 0.96 & $\begin{array}{c}-2.06 \\
\text { (horizontal) }\end{array}$ \\
\hline Invert & -3.07 & 4.53 & -52.33 \\
\hline
\end{tabular}

The analysis of the obtained data shows that notation of defects allows to calculate more precisely the decrease in lining carrying capacity.

The following result has been estimated:

1. Nonhomogeneity of lining concrete resistance power leads to decrease in carrying capacity on average by $17.3 \%$

2. Modeling of internal voids behind the lining leads to the increase of principal stress $\sigma 3$ in the finite elements of lining, placed close to a defect, by $7.4 \%$.

3. Modeling of the surface damage of the lining leads to the increase of principal stress $\sigma 3$ in the finite elements of lining elements, placed close to a defect, by $12.4 \%$, and stress $\sigma 3$ increases by 2.1 times.

4. Modeling of the tunnel invert under a ballast section leads to the increase of the principal stress $\sigma 1$ and $\sigma 3$ by 2-3 times in comparison with the design value construction.

\section{Conclusions}

The results of the investigation reflect that defects a lining and beyond lining space can have a considerable impact on the stress-strain state of a construction. However the staged approach to assessment of engineering status of a tunnel not always allows to reveal hazardous processes in the considered geotechnical system and to realize effective protective measures at the appropriate times. It is essential not only to analyze separate operational stages of a tunnel, but also provide an information modeling of the lifespan of an object by creation of information model using BIM technologies [4-10].

At the present time, BIM technologies actively implement into many fields of industrial, civil and transport facilities design. The benefits are a matter of common knowledge but, in relation to railway tunnels with long working lifespan and similar objects, aren't always obvious. If during designing regular buildings and constructions we consider constructions with the known design parameters, in this case it is essential to describe the complicated natural-anthropogenic system in the right manner, due to it is subject to impact of uncertain factors.

The general algorithm of assessment and maintenance of operating engineering status of a tunnel with an application of BIM technologies should include the following stages:

1. Carrying out essential geotechnical and geophysical researches on the route of a tunnel.

2. Tunnel structures monitoring system development and deployment.Collection and analysis of data [11].

3. Regular control of a tunnel by the railcar with the measuring station (ERA type).

4. Creation of a tunnel digital model, filling it with data, regular updating and checking calculations.

5. Development and implementation of essential repair actions. 
The approach will demand sufficiently expensive researches with the involvement of highly qualified specialists. The process of information modeling is labor-consuming, requires an application of specialized software and a high-performance computer. Therefore in the current context it can be recommended for critical tunnels with a long working lifespan, above-limit abrading of constructions and also for objects where rather major accidents.

\section{References}

1. M.S. Pleshko,Inženernyj vestnik Dona 1, 12 (2014)

2. A.Ju.Prokopov, M.V.Prokopova, M.A. Rotenberg, Osvoenie podzemnogo prostranstva megapolisov7, 101-109(2013)

3. M.S.Pleshko, S.G. Stradanchenko, S.A. Maslennikov, O.V. Pashkova, ARPN Journal of Engineering and Applied Sciences 10, 14 - 19(2015)

4. A.V. Skvorcov,SAPR i GIS avtomobil'nyh dorog,2(3), 22-32 (2014)

5. J.Daller, M.Žibert, C.Exinger, M.Lah, Geomechanics and Tunnelling9, 674 - 683 (2016)

6. J.Wang, X.Hao, X.GaoRobotics and Automation 1, 195-204 (2015)

7. Z.Jian-ping, L.Ding, L.Jia-rui, Construction Technology 41(371), 10-14 (2012)

8. X.You-quan, L.Liu Xin, Journal of Engineering Management 27(1),44-47 (2013)

9. R.Heikkilä, A.Kaaranka, T.Makkonen, Automation and Robotics in Construction and Mining1, 672-675 (2014)

10. X.Shen, M.Lu, S.Mao, X.Wu Integrated, Automation and Robotics in Construction and Mining 1,103-109 (2014)

11. S.G.Stradanchenko, M.S. Pleshko, V.N. Armejskov, Inženernyj vestnik Dona 4, 52 (2004) 